\title{
The different activities of RNA G-quadruplex structures are controlled by flanking sequences
}

\author{
Alice J-L Zheng ${ }^{1, \star}$, Aikaterini Thermou ${ }^{1,4, *}$, Pedro Guixens Gallardo ${ }^{6,7}$, Laurence Malbert-Colas ${ }^{1}$, \\ Chrysoula Daskalogianni ${ }^{1,4}$, Nathan Vaudiau ${ }^{1}$, Petter Brohagen ${ }^{1}$, Anton Granzhan ${ }^{6,7}$, Marc Blondel $^{8}$ (D), \\ Marie-Paule Teulade-Fichou ${ }^{6,7}$, Rodrigo Prado Martins ${ }^{5}$ (D), Robin Fahraeus ${ }^{1,2,3,4, \star}$ (]
}

The role of G-quadruplex (G4) RNA structures is multifaceted and controversial. Here, we have used as a model the EBV-encoded EBNA1 and the Kaposi's sarcoma-associated herpesvirus (KSHV)encoded LANA1 mRNAs. We have compared the G4S in these two messages in terms of nucleolin binding, nuclear mRNA retention, and mRNA translation inhibition and their effects on immune evasion. The G4s in the EBNA1 message are clustered in one repeat sequence and the $\mathrm{G} 4$ ligand PhenDH2 prevents all G4-associated activities. The RNA G4S in the LANA1 message take part in similar multiple mRNA functions but are spread throughout the message. The different G4 activities depend on flanking coding and noncoding sequences and, interestingly, can be separated individually. Together, the results illustrate the multifunctional, dynamic and context-dependent nature of G4 RNAs and highlight the possibility to develop ligands targeting specific RNA G4 functions. The data also suggest a common multifunctional repertoire of viral G4 RNA activities for immune evasion.

DOI 10.26508/lsa.202101232 | Received 11 September 2021 | Revised 8 November 2021 | Accepted 8 November 2021 | Published online 16 November 2021

\section{Introduction}

RNA-protein interactions are key regulators of the selective processing of RNAs which includes RNA splicing, localisation, translation, and stability, and are therefore involved in various cellular processes (Lewis et al, 2017; Duss et al, 2019; Rodgers \& Woodson, 2019) including embryonic development (Beaudoin et al, 2018), neuronal activity (Lin et al, 2020), and oncogenesis (Ceci et al, 2021), to mention some. RNA secondary structures serve as binding platforms for the RNA-binding proteins, determine the assembly of ribonucleoprotein complexes and consequently affect gene expression (Lewis et al, 2017; Beltran et al, 2019; Duss et al, 2019; Rodgers \&
Woodson, 2019; Sanchez de Groot et al, 2019). This is well illustrated by riboswitches and internal ribosome entry sites (IRESs) that control prokaryotic and eukaryotic/viral gene expression, respectively (Jackson et al, 2010; Serganov \& Nudler, 2013). These regulatory elements are usually located in the $5^{\prime}$ UTRs but RNA structures within the coding sequences can also mediate translation. However, little is yet known about the dynamics and regulation of RNA structures in vivo.

G-quadruplexes (G4) are secondary structures found in both RNA and DNA that are formed by the stacking of at least two G-quartets, which are planar arrangements of four guanines connected by Hoogsten hydrogen bonds (Fay et al, 2017; Reznichenko et al, 2019). G4 conformation diversity depends on directionality (parallel, antiparallel, and hybrid), on the number of stacked G-quartets and on the length and sequence of the loops connecting the different strands, affecting stability and binding capacity to specific factors (Harris \& Merrick, 2015; Tosoni et al, 2015; Fay et al, 2017). RNA G4 structures are linked to translation suppression when present in 5' UTR of the mRNA (Beaudoin \& Perreault, 2010; Endoh \& Sugimoto, 2016; Herdy et al, 2018) and to ribosome stalling when placed in the ORF (Endoh and Sugimoto, 2013, 2016; Endoh et al, 2013a, 2013b). Despite being associated with important functions, the actual formation, stability, and activity of RNA G4S in vivo is still poorly understood and controversial and most of the predicted G4-forming sequences in RNAs do not form stable G4 structures in eukaryotes (Guo \& Bartel, 2016). On the other hand, G4 structures in vitro using shorter RNA sequences show high thermostability (Arora \& Maiti, 2009).

RNA G4S are implied across various virus families, such as Flaviviridae (Fleming et al, 2016; Wang et al, 2016a; Jaubert et al, 2018), Herpesviridae (Murat et al, 2014), Filoviridae (Wang et al, 2016b), Paramyxoviridae (Majee et al, 2020), Retroviridae (Ruggiero et al, 2019), and Coronaviridae (Bezzi et al, 2021; Ji et al, 2021; Lavigne et al, 2021; Zhao et al, 2021), making them potential targets for drug development. In HIV-1, RNA G4S play an important role in the packaging of the virions (Lyonnais et al, 2003) and are part of the dimerisation process of the

\footnotetext{
${ }^{1}$ Inserm UMRS1131, Institut de Génétique Moléculaire, Université Paris 7, Hôpital St. Louis, Paris, France ${ }^{2}$ RECAMO, Masaryk Memorial Cancer Institute, Brno, Czech Republic ${ }^{3}$ Department of Medical Biosciences, Umeå University, Umeå, Sweden ${ }^{4}$ ICCVS, University of Gdańsk, Science, Gdańsk, Poland ${ }^{5}$ ISP, INRAE, Université de Tours, UMR1282, Tours, France ${ }^{6}$ CNRS UMR9187, INSERM U1196, Institut Curie, PSL Research University, Orsay, France ${ }^{7}$ CNRS UMR9187, INSERM U1196, Université Paris Sud, Université Paris-Saclay, Orsay, France ${ }^{8}$ Inserm UMR1078, Université de Bretagne Occidentale (UBO), Etablissement Français du Sang (EFS) Bretagne, CHRU Brest, Brest, France
}

Correspondence: robin.fahraeus@inserm.fr

*Alice J-L Zheng, Aikaterini Thermou, and Robin Fahraeus contributed equally to this work 
two copies of the HIV-1 RNA genome, facilitating recombination during reverse transcription (Marquet et al, 1991, 1994; Piekna-Przybylska et al, 2013; Métifiot et al, 2014). In HCV, RNA G4S are implicated in the translation and replication of the genomic RNA (Wang et al, 2016a; Jaubert et al, 2018). EBNA1 and LANA1 are essential genome maintenance proteins of the EBV and the Kaposi's Sarcoma-associated herpesvirus (KSHV), respectively (Lan et al, 2004; Münz, 2015). Both are highly antigenic and to allow the viruses to escape immune surveillance the translation of their respective messenger RNAs is kept at the minimum to prevent the production of antigenic peptide substrates for the MHC-I pathway (Yin, 2003; Kwun et al, 2007). The synthesis of antigenic peptides for the MHC-I pathway is via non-canonical translation that is distinct from the canonical translation which generates full-length proteins, in line with the notion that fulllength proteins are a poor substrate for antigenic peptides (Cardinaud et al, 2004; Starck et al, 2008; Apcher et al, 2011; Wei et al, 2019; Yewdell et al, 2019). A glycine-alanine repeat (GAr) domain in EBNA1 is encoded by a guanine-rich sequence that forms G4 structures and binds nucleolin (NCL), inhibiting canonical and non-canonical translation initiation in cis to support viral immune evasion but how G4 structures support these different activities is not known (Yin, 2003; Apcher et al, 2009; Lista et al, 2017b; Martins et al, 2019). More recently, it was shown that the mRNA translation stress caused by the GAr domain activates the E2F1 oncogene and stimulates c-myc and ribosomal biogenesis (Gnanasundram et al, 2017). Hence, by suppressing its own synthesis, EBNA1 evades the immune system and promotes cell proliferation. The LANA1 of the KSHV also uses a cis-acting mechanism to evade immune surveillance (Murat et al, 2014) and as for EBNA1, both RNA G4 structures and repeat domains of LANA1 plays an important role in translation regulation for both full-length proteins and antigenic peptides production (Kwun et al, 2007; Apcher et al, 2009; Murat et al, 2014; Dabral et al, 2019). However, two main differences are worth being noticed when comparing these two functionally similar mRNAs and proteins, whereas the G4S in EBNA1 are located in the GArencoding domain, the G4S of LANA1 are spread throughout the message (Murat et al, 2014; Dabral et al, 2019). In addition, the peptide repeats of LANA1 and EBNA1 are different, although both are encoded by mRNA sequences predicted to form G4S.

We have used the properties of the EBNA1 and the LANA1 mRNAs to study the multifunctional aspects of G4 RNA structures. Each message has different G4 structures encoding different peptide sequences but share functional similarities in suppressing mRNA translation in cis, interacting with NCL and preventing mRNA export. The functions of their respective G4S can be separated by alterations in the flanking sequences and together with the observation that RNA G4S can reform in cells, these results illustrate how multifunctional and dynamic G4 structures act together to support viral immune evasion strategies. This sheds new light on some of the controversies surrounding the stability of G4 RNA structures and illustrates the importance of the context in which they are placed.

\section{Results}

\section{G4 ligands PhenDC3 and PhenDH2 bind LANA1 mRNA G4 structures in vitro}

Using the QGRS mapper tool, and according to the work of Dabral et al (2019), the LANA1 message can form G4 structure at multiple points on the mRNA, but mostly in the region encoding the Central Repeat Domain of LANA1 (Fig 1A). To confirm the binding of the G4 ligands we selected, namely, PhenDC3 and PhenDH2, on LANA1 RNA G4 structures, two quadruplex-prone G-rich short RNA sequences (LANA13 and LANA16 with QGRS scores of 21 and 18, respectively, Fig 1B) from the LANA1 Central Repeat (CR) domains, which have been already identified for their potential to form multiple quadruplex structures (Dabral et al, 2019), have been selected. First, to experimentally verify the RNA capacity to fold into quadruplex, their circular dichroism (CD) spectra were recorded (Fig 1B). In both cases, a positive peak at $265 \mathrm{~nm}$ together with a broad shoulder around $300 \mathrm{~nm}$ was observed. The CD spectra indicated the coexistence of different conformations in equilibrium, where the parallel conformation was the predominant. The RNA sequences exhibited a negative transition at $295 \mathrm{~nm}$ in the UV melting experiments which is characteristic of $\mathrm{G} 4$ unfolding (Fig 1C) and allowed determining Tm values of $65-68^{\circ} \mathrm{C}$ and $45-48^{\circ} \mathrm{C}$ for LANA13 and LANA16, respectively. In presence of PhenDC3 or PhenDH2, the $C D$ intensity is slightly decreased indicating that interaction is occurring between the G4 conformation and the ligands (Fig 1B). Interestingly, when PhenDC3 was added before the annealing step, the shoulder at $300 \mathrm{~nm}$ was not observed (Fig S1), thereby suggesting that the ligand shifts the equilibrium towards the parallel conformation as has been recently reported for other $\mathrm{G} 4$ sequences (Aznauryan et al, 2021). Finally, we monitored the effects of PhenDH2 and PhenDC3 on the RNA sequences by $C D$ melting. PhenDH2 and PhenDC3 induced on LANA16 a very strong stabilization $\left(\triangle \mathrm{Tm}=40^{\circ} \mathrm{C}\right.$ for PhenDH2 and $>47^{\circ} \mathrm{C}$ with incomplete melting $\mathrm{Tm}>95^{\circ} \mathrm{C}$ for PhenDC3) (Fig 1D). No complete melting of the G4 of LANA13 could be achieved in the presence of any ligand, indicating a very strong stabilization effect. Taken together, these data support the formation of G4 structures within the LANA1 CR domains and the possibility of targeting them with high affinity ligands such as PhenDC3 and PhenDH2.

\section{G4 ligands affect LANA1 mRNA nuclear export, translation, and nucleolin binding}

The glycine-alanine repeat (GAr) domain of the EBV-encoded EBNA1 mediates a unique cis-acting suppression of its own synthesis via G4 RNA structures to minimise the production of EBNA1derived antigenic peptides for the MHC-1 pathway (Yin, 2003; Lista et al, 2017b). Similarly, the LANA1 of the KSHV also uses a cis-acting mechanism to evade the immune system via its CR domains (Kwun et al, 2007). Whereas the GAr-encoding message consists of GC-rich sequences encoding single alanine residues separated by two or three glycines, the CR domains of LANA1 are also GC rich, but each repeat region encodes for a different peptide motif (Kwun et al, 2007).

To know if LANA1 and EBNA1 are using similar molecular mechanisms involving RNA G4 structures to control mRNA translation, we first treated KSHV-carrying lymphoma B cells (BCP-1) and the EBV-carrying B-cell line B95.8 with $2 \mu \mathrm{M}$ of the $\mathrm{G} 4$ ligands PhenDC3 or PhenDH2 for $24 \mathrm{~h}$ (Reznichenko et al, 2019). This resulted in an increase in the expression of respective proteins (Fig 2A). For EBNA1, this is linked to prevention of NCL binding to the RNA G4S by the G4 ligands (Lista et al, 2017a, 2017b). Thus, this result 
A
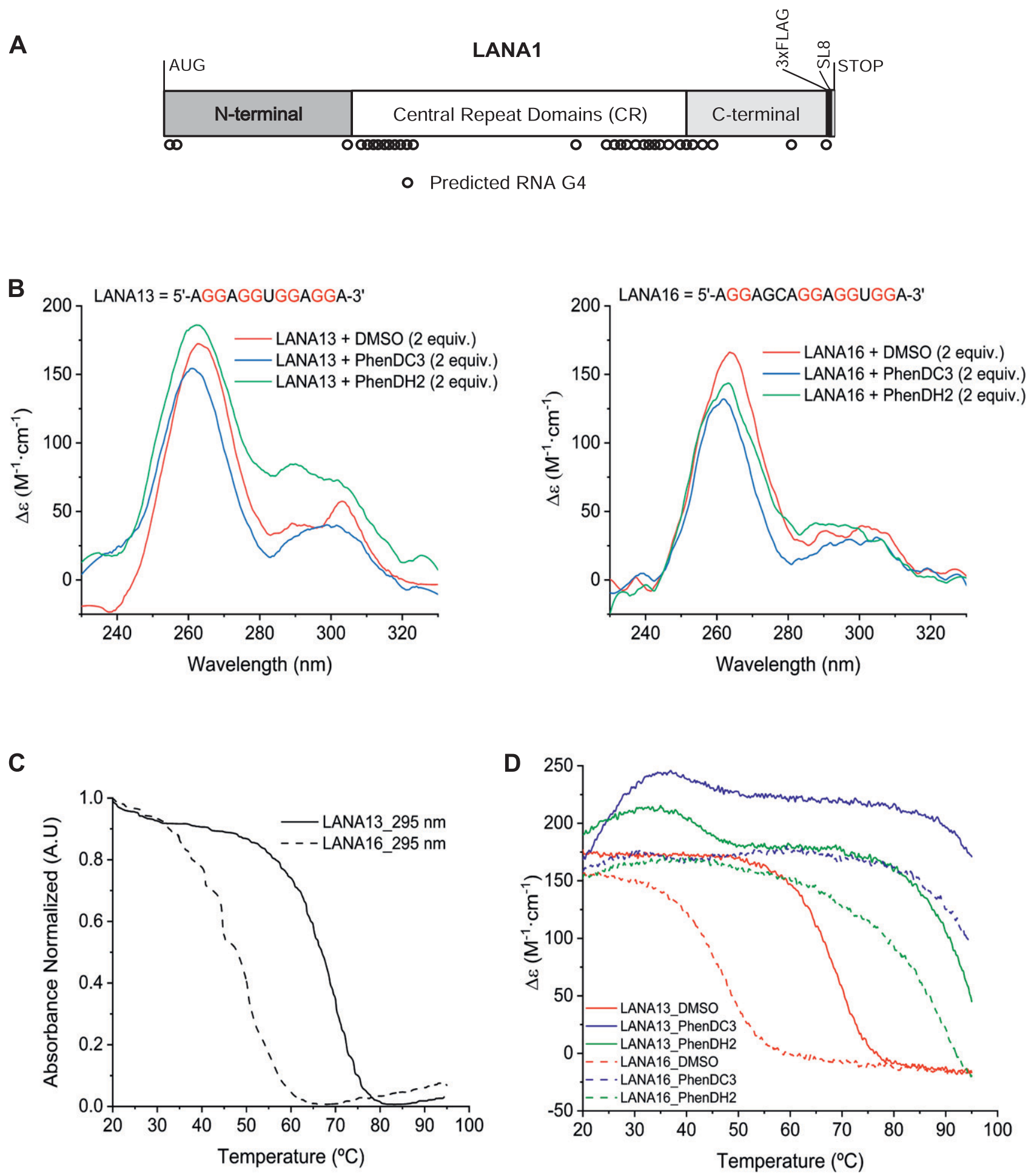

Figure 1. LANA1 central domains encoding mRNA form G4 structures in vitro.

(A) CDNA construct encoding LANA1 with a FLAG-tag and the SL8 MHC-1 antigenic peptide sequence in its C-terminus. Circles underneath represent the 32 predicted RNA G4 structures. (B) Circular dichroism spectra of RNA fragments ( $5 \mu \mathrm{M}$ ) of LANA1 CR domain in the presence of PhenDC3 (blue), PhenDH2 (green) or without ligand (red). Left, RNA-13mer (LANA13); right, RNA 16-mer (LANA16). (C) UV melting experiment at $295 \mathrm{~nm}$ of LANA13 (straight line) or LANA16 (dashed line) RNA sequences. (D) Circular dichroism melting experiment recorded at $262 \mathrm{~nm}$ of LANA13 (straight line) or LANA16 (dashed line) in the presence of PhenDC3 (blue), PhenDH2 (green), or without ligand (red). 
A

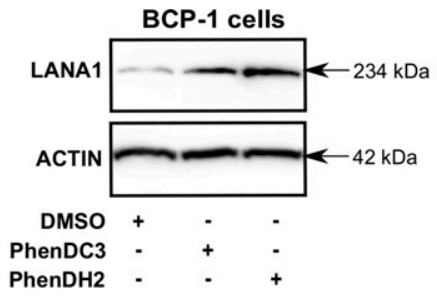

B

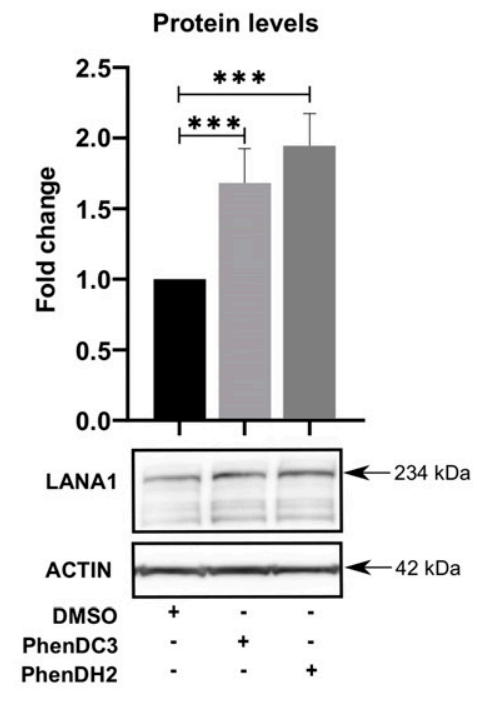

D
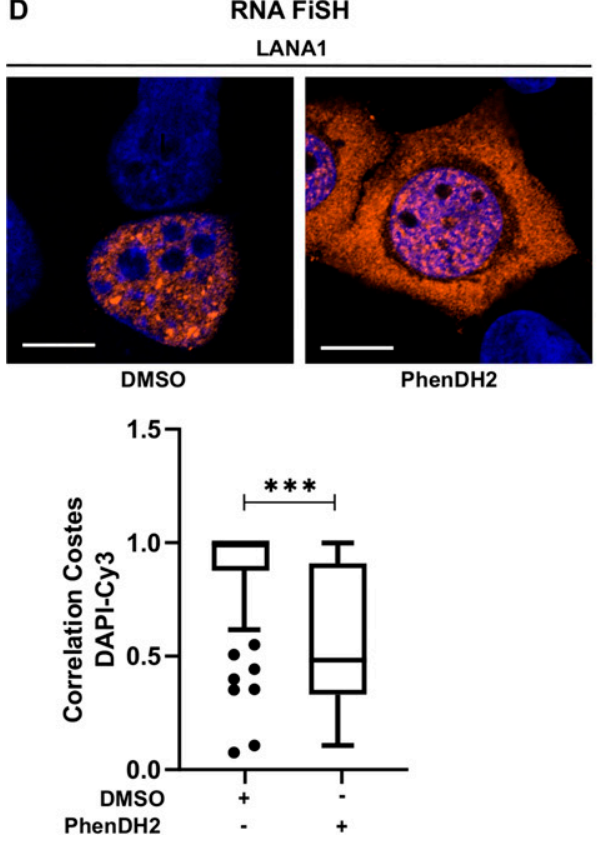

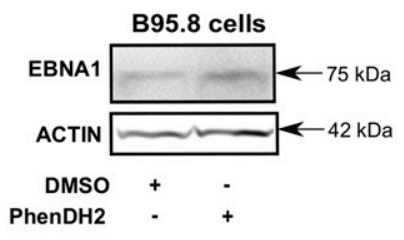

C

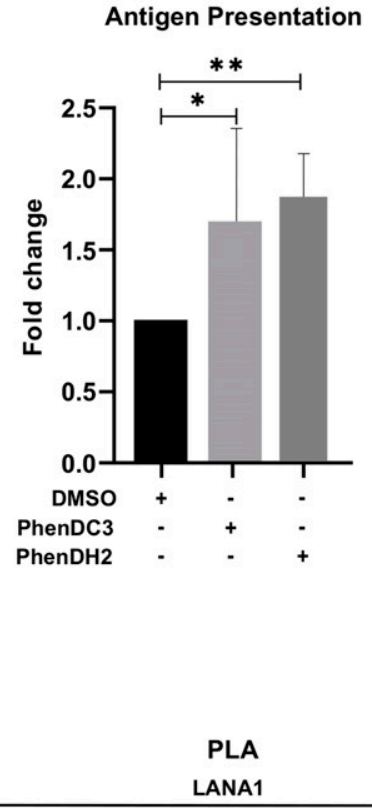

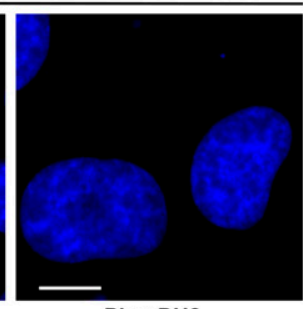

PhenDH2

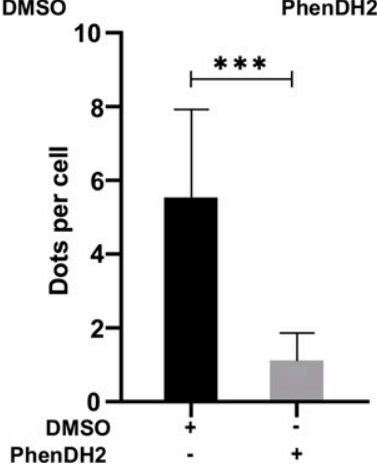

Figure 2. G4 RNA structures control the translation and processing of the LANA1 mRNA.

(A) Western blots (WB) show the expression of LANA1 in KSHV-infected BCP-1 cells (left) or EBNA1 in EBVinfected B95-8 cells (right) after treatment with $2 \mu \mathrm{M}$ of $\mathrm{G} 4$ ligands PhenDC3, PhenDH2, or DMSO for $24 \mathrm{~h}$. WB show one of at least three similar experiments. (B) WB (below) shows the expression of LANA1 from CDNA construct presented in Fig $1 \mathrm{~A}$ after indicated treatments. The graph above shows expression relative to actin from three independent experiments. WB shows one of at least three similar experiments. (C) Relative amount of SL8 antigen peptide produced from the LANA1 CDNA presented in Fig $1 \mathrm{~A}$ under similar conditions in H1299 cells expressing the murine MHC-I (Kb). The levels were estimated by measuring IL2 release from OT1 CD8 ${ }^{+} \mathrm{T}$ cells. (D) LANA1 mRNA localisation (RNA FiSH) in H1299 cells transfected with the LANA1 construct presented in Fig $1 \mathrm{~A}$ after PhenDH2 or DMSO treatment. The boxplot graph below shows Costes Correlation factor for cytoplasmic versus nuclear localisation. (E) The proximity ligation assay shows the interaction between the LANA1 mRNA and nucleolin (NCL) (white dots) after PhenDH2 treatment. The graph below shows the average interactions per cell from three independent experiments. Scale bar corresponds to $10 \mu \mathrm{m}$. shows that G4 structures in the LANA1 message, like in the EBNA1 message, are involved in translation suppression.

We next expressed a FLAG-tagged LANA1 construct (Fig 1A) in human H1299 carcinoma-derived cells and we observed a similar increase in protein levels after PhenDC3 and PhenDH2 treatment (Fig 2B), showing that the G4-mediated translation control is not dependent on cell line or on the presence of the whole viral genome, as for EBNA1 (Lista et al, 2017b). Unlike PhenDC3 and 
PhenDH2, another $\mathrm{G} 4$ ligand, the pyridostatin (PDS), is not able to interfere with the inhibition of LANA1 expression (Fig S2A), similarly to what was shown with EBNA1 (Lista et al, 2017b). We also inserted an eight amino acid-MHC-I antigenic peptide sequence (SL8) derived from the chicken ovalbumin gene (Ova) in the C-terminus of LANA1. The SL8 peptide is specifically recognised by $\mathrm{CD}^{+} \mathrm{T}$ cells (OT-1) when presented on the murine MHC-I (Kb) (Martins et al, 2019). After transient expression of LANA1 together with $\mathrm{Kb}$ in $\mathrm{H} 1299$ cells, we observed a twofold activation of $C D 8^{+} \mathrm{T}$ cells after $\mathrm{G} 4$ ligand treatment, meaning that more SL8 antigenic peptide substrates were synthesised (Fig 2C), whereas the PDS is not able to interfere with the production of antigenic peptides for $\mathrm{MCH}-\mathrm{I}$ pathway (Fig S2B). As PhenDH2 is a more potent G4 ligand when it comes to EBNA1 mRNA compared with PhenDC3 (Reznichenko et al, 2019), we focused our investigation on PhenDH2 treatment. By using RNA FiSH, we observed that the LANA1 mRNA is located in the nucleus and that treatment with $\mathrm{PhenDH} 2$ promoted a cytoplasmic location (Fig 2D). Furthermore, using the proximity ligation assay (PLA) we showed that PhenDH2 interferes with the LANA1 mRNAnucleolin (NCL) interaction in situ (Fig 2E).

These results show that the EBV and KSHV have evolved a common strategy to exploit cis-acting G4 mRNA structures in the EBNA1 and LANA1 messages to prevent the production of antigenic peptide substrates for the MHC-1 pathway.

\section{Deleting the LANA1 CR domain overcomes nuclear retention and stimulates synthesis of antigenic peptide substrates but does not affect the synthesis of full-length proteins or the interaction with nucleolin}

It has been suggested that the CR domains of the LANA1 account for mRNA translation control (Kwun et al, 2007) and we wanted to know if $\mathrm{G} 4$ activity in this region mediates the same functions as the EBNA1-encoded GAr sequence. When we deleted the CR domains (LANA1 $\triangle C R$ ), we observed no, or little, change in LANA1 protein expression, whereas we observed an average $60 \%$ increase in antigen presentation, indicating that different G4-forming domains in LANA1 control translation of antigenic peptide substrates and full-length proteins (Fig 3A-C). RNA FISH analysis detected most LANA1 $\triangle C R$ messages in the cytoplasm (Fig 3D). The PLA showed NCL-LANA1 $\triangle C R$ mRNA interactions in the nucleus, even though the number of interactions were reduced when compared with fulllength LANA1 (Fig 3E). It should be pointed out that NCL is nuclear and preventing nuclear retention of the mRNAs could be sufficient to explain the differences in number of interactions.

Thus, G4 structures of the CR domain of the LANA1 message mediate nuclear retention and control of antigenic peptide synthesis but not full-length protein synthesis and NCL interaction.

\section{G4S outside the CR domains control LANA1 protein expression and nucleolin binding}

The above results indicate that different LANA1 mRNA processing activities can be mediated by individual G4 structures throughout the LANA1 message. To test if NCL binding and the control of fulllength protein synthesis of the LANA1 $\triangle C R$ construct is mediated by G4S predicted outside the CR domain, we treated cells expressing
LANA1 $\triangle C R$ with PhenDH2. This resulted in an average $50 \%$ increase in protein levels (Fig 4A) and antigen presentation (Fig 4B). The treatment did not significantly affect $L A N A 1 \triangle C R$ mRNA localisation (Fig 4C) but prevented furthermore the interaction with NCL (Fig 4D).

This confirms that the cis-mediated regulation of LANA1 mRNA translation is more complex as compared with the EBNA1 and involves G4S from different regions of the coding sequence and not just from the CR domains.

\section{The position of the G4s within the coding sequence controls its activity}

It has been suggested that the interaction between NCL and G4S of EBNA1 mRNA is sufficient for suppressing synthesis of antigenic peptides and full-length proteins (Lista et al, 2017b), and it was surprising to see that deletion of the CR differentiates these two activities in the LANA1 mRNA. Therefore, we were interested to know if the $\mathrm{G} 4$ activities of the EBNA1 message can also be separated. To test this, we used constructs in which the GAr was fused to the $5^{\prime}$ or the $3^{\prime}$ end of the chicken ovalbumin (Ova) ORF, resulting in fusion proteins with the GAr in the $\mathrm{N}$ terminus or the $\mathrm{C}$ terminus (GAr-Ova and Ova-GAr, respectively) (Fig 5A) (Yin, 2003). Both messages retained their nuclear localisation but the expression of the GArOva fusion protein was considerable less, as compared with the Ova-GAr, whereas the RNA levels followed an opposite trend (Figs $5 B$ and $C$ and $S 3$ ). When we isolated these RNAs from transiently transfected cells and compared their binding capacity to recombinant NCL, we observed that the GAr-Ova mRNA had a higher affinity to NCL compared with the Ova-GAr mRNA (Fig 5D).

Hence, the location of the GAr G4S within the coding sequence of the message determines NCL binding and mRNA translation inhibitory activity but not nuclear retention. Of note, these results support the notion that NCL plays no role in G4-dependent mRNA export.

\section{Flanking UTR sequences affect LANA1 and EBNA1 G4s differently}

The GAr-Ova and the Ova-GAr reporter constructs showed that the localisation of the G4-containing translational inhibitory sequence within the coding sequence is important for some, but not all, G4related activities. We next wanted to know if changes in the noncoding sequences can also affect G4 functions. We introduced RNA structures in the form of the c-myc and HCV IRESs in the 5' UTR of the GAr-Ova construct. We could confirm that the c-myc-GAr-Ova construct and c-myc-Ova are equally efficiently translated (Apcher et al, 2009). The fusion of the HCV IRES (HCV-GAr-Ova) instead further suppressed expression of GAr-Ova as well as Ova alone (HCV-Ova) (Fig 6A) (Martins et al, 2019). When the two IRESs were individually fused to the LANA1 message, they both stimulated synthesis of full-length proteins (Fig 6B). Interestingly, although only the HCV IRES suppressed synthesis of GAr-Ova and Ova proteins, the presence of either IRES in the 5' UTRs resulted in an increase in the synthesis of antigenic peptide substrates from GArOva and LANA1 messages (Fig 6C and D). Hence, although the HCV IRES suppressed expression of full-length GAr-Ova and Ova, it stimulated synthesis of antigenic peptide substrates from both GAr-Ova and LANA1 messages. Both IRESs also prevented NCL 
A

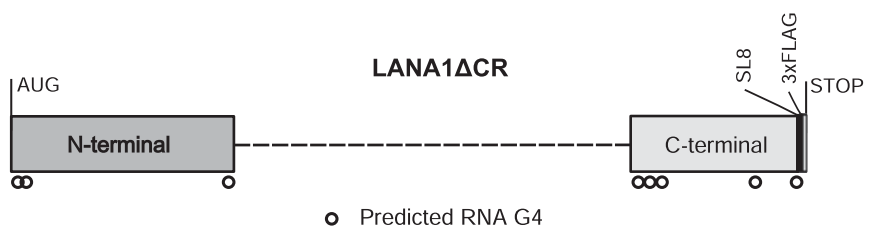

B

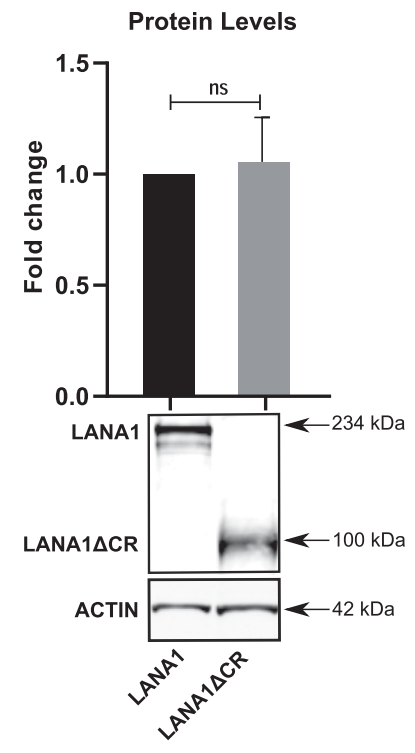

c

Antigen Presentation

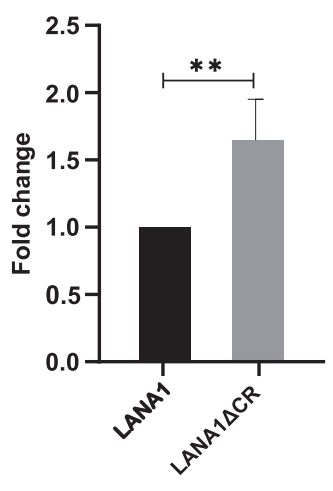

D

RNA FiSH
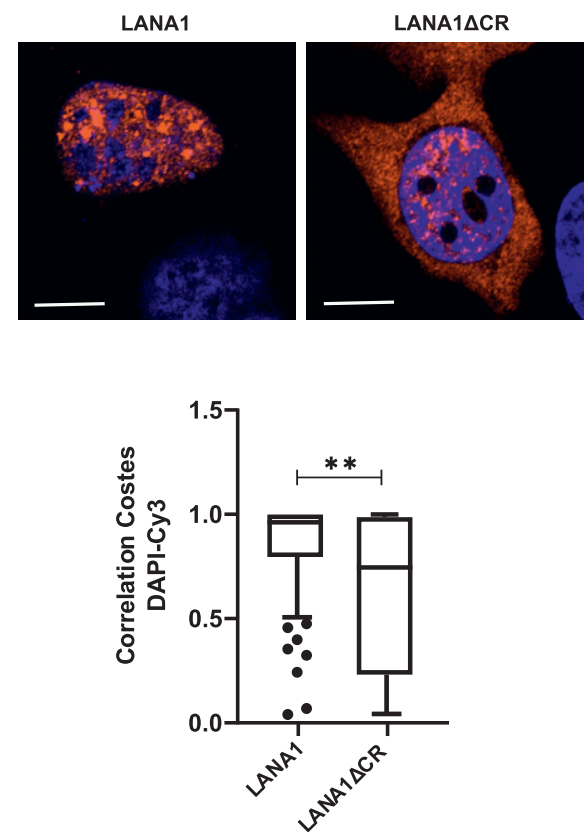

binding to GAr-encoding and LANA1 mRNAs, but only the HCV IRES promoted mRNA nuclear export (Figs $6 \mathrm{E}$ and S4-S6). Fusing the c-myc and the HCV structures to the 3' UTR of LANA1 had little effects on $\mathrm{G} 4$ activities (Fig S7A and B).
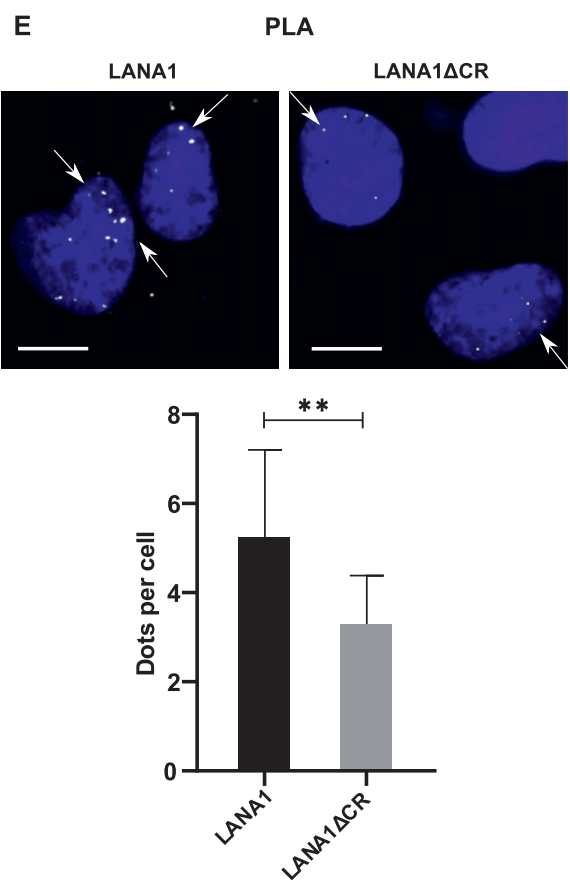

Figure 3. Central repeat (CR) domains of the LANA1 mRNA control antigen

presentation, nuclear retention but not canonical translation for production of fulllength protein or nucleolin interaction.

(A) CDNA construct encoding LANA1 without CR domains (LANA1 $\triangle C R$ ) and with a FLAG Tag and the SL8 in the C terminus. Circles underneath the rectangles represent the eight predicted RNA G4 structures. (B) WB of H1299 cells transfected with the LANA1 or LANA1 $\triangle$ CR constructs. Graph shows relative protein levels, adjusted to corresponding actin control. WB shows one of at least three similar experiments. (c) Relative antigen presentation levels estimated by measuring IL2 release by OT1 cells after incubation with H1299 cells expressing murine MHC-I (Kb). (D) LANA1 mRNA localisation (RNA FiSH) with boxplot graph below representing three independent experiments. (E) The interaction with NCL and the LANA1 mRNA (PLA NCL-LANA1 mRNA) in H1299 cells transfected with indicated CDNA constructs. The graph below shows the average of three independent experiments. Scale bar corresponds to $10 \mu \mathrm{m}$. 
A

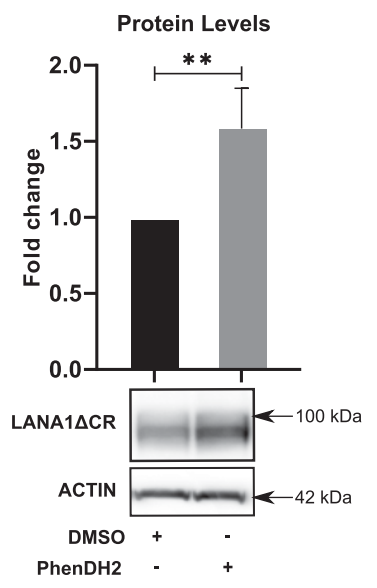

C

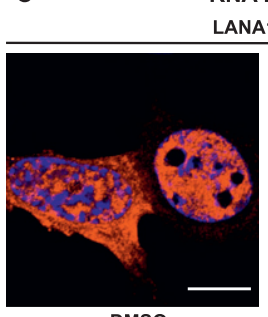

DMSO

RNA FiSH

$A 1 \Delta C R$
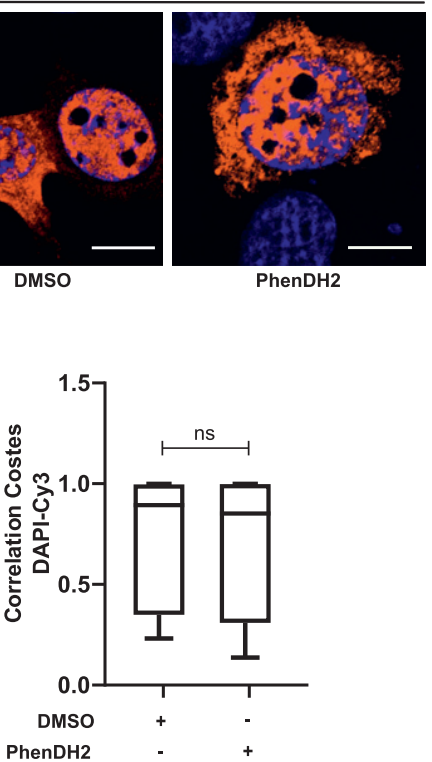

B

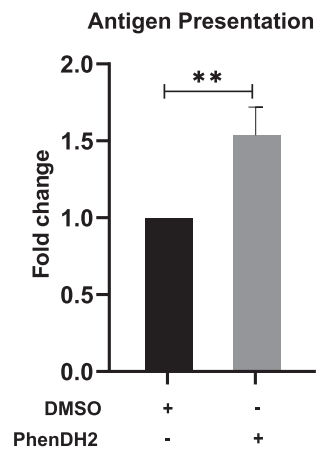

D

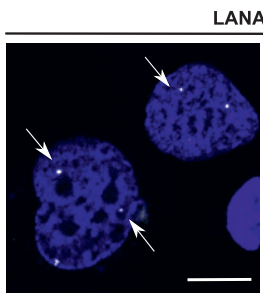

DMSO
PLA

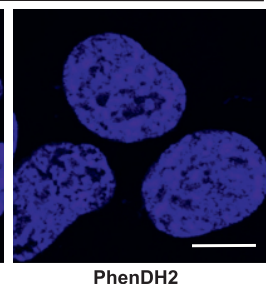

Figure 4. G4 structures outside the central repeat (CR) of LANA1 control NCL binding and canonical translation.

(A) WB from H1299 cells expressing LANA1 $\triangle$ CR treated with the G4 ligands PhenDH2 or DMSO. Graph shows relative protein levels adjusted with the corresponding actin levels. WB shows one of at least three similar experiments. (B) Relative antigen presentation estimated by measuring IL2 release by OT1 cells after incubation with $\mathrm{H} 1299$ cells expressing murine MHC-I (Kb) and LANA1 $\triangle C R$ and treated with PhenDH2 or DMSO. (C) LANA1 $\triangle C R$ mRNA localisation (RNA FiSH). (D) Proximity ligation assay showing the RNA-NCL interaction (proximity ligation assay NCL-LANA1 mRNA) in $\mathrm{H} 1299$ cells transfected with LANA1 $\triangle$ CR construct after PhenDH2 or DMSO treatment. The graphs show the average of three independent experiments. Scale bar represents $10 \mu \mathrm{m}$.

\section{Discussion}

We have compared four different activities related to G4 structures within the coding sequences of the KSHV- and EBV-encoded LANA1 and EBNA1, respectively. These proteins play similar key roles in maintaining viral genome integrity and both are expressed in all virus-infected cells, including cancerous ones, making their respective expression interesting therapeutic targets for virusassociated diseases (Ballestas, 1999; Ballestas \& Kaye, 2001; Ciufo et al, 2001; Kwun et al, 2007; Münz, 2015). Both viruses need to ensure that the production of peptide substrates for the MHC-I pathway is kept at a minimum to evade the immune system (Kwun et al, 2007; Murat et al, 2014). To achieve this, they have evolved cis-acting mechanisms to suppress translation of the LANA1 and EBNA1 messages. Even though the peptide sequences mediating this effect are not similar (Kwun et al, 2007), the concept to control mRNA processing and translation to achieve immune evasion is. This suggests that controlling their own rate of translation might be a common strategy whereby, at least latent, viral messages evade the immune system. In agreement with this hypothesis is the observation that viruses causing persistent infections in Metazoa hosts are significantly enriched with putative G-quadruplex forming sequences (PQS), whereas viruses causing acute infections are significantly depleted in PQS (Bohálová et al, 2021).

Treatment with the $\mathrm{G} 4$ ligand PhenDH2 resulted in an increase in protein expression, antigen presentation, nuclear export, and loss of NCL binding in the context of EBNA1 and LANA1, indicating that these four events are indeed all G4 dependent. The G4S of EBNA1 mRNA are mostly clustered within the gly-ala repeat GAr-encoding sequence (Murat et al, 2014), whereas the G4 activities of LANA1 are spread throughout the message. The G4S in the CRs of LANA1 are determinant for nuclear mRNA retention and suppression of antigenic peptide substrates, whereas G4s outside the CR domains are important for canonical translation control and nucleolin interaction. Both CR and non-CR-related G4S play roles in antigen production. The fact that the $\mathrm{CR}$ domains play an important role in 
A
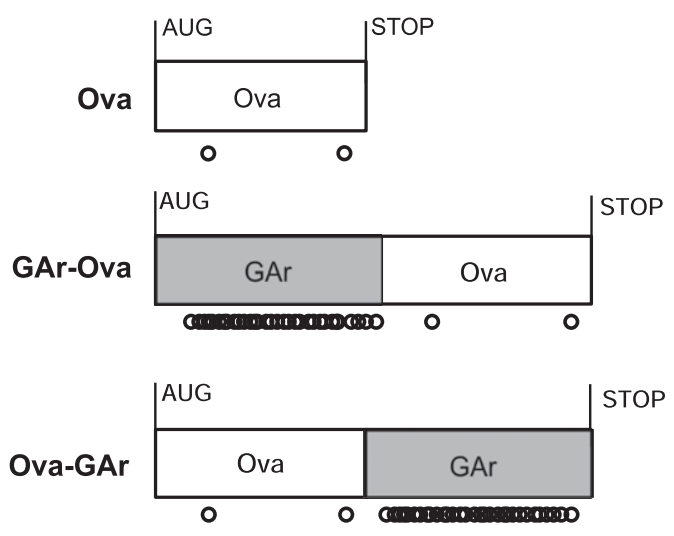

- Predicted RNA G4
B

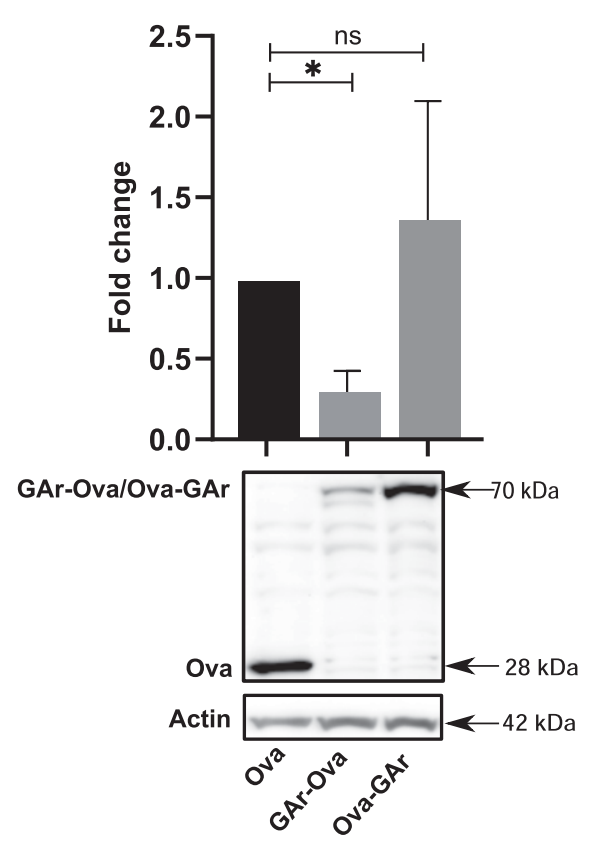

D

C

RNA FiSH
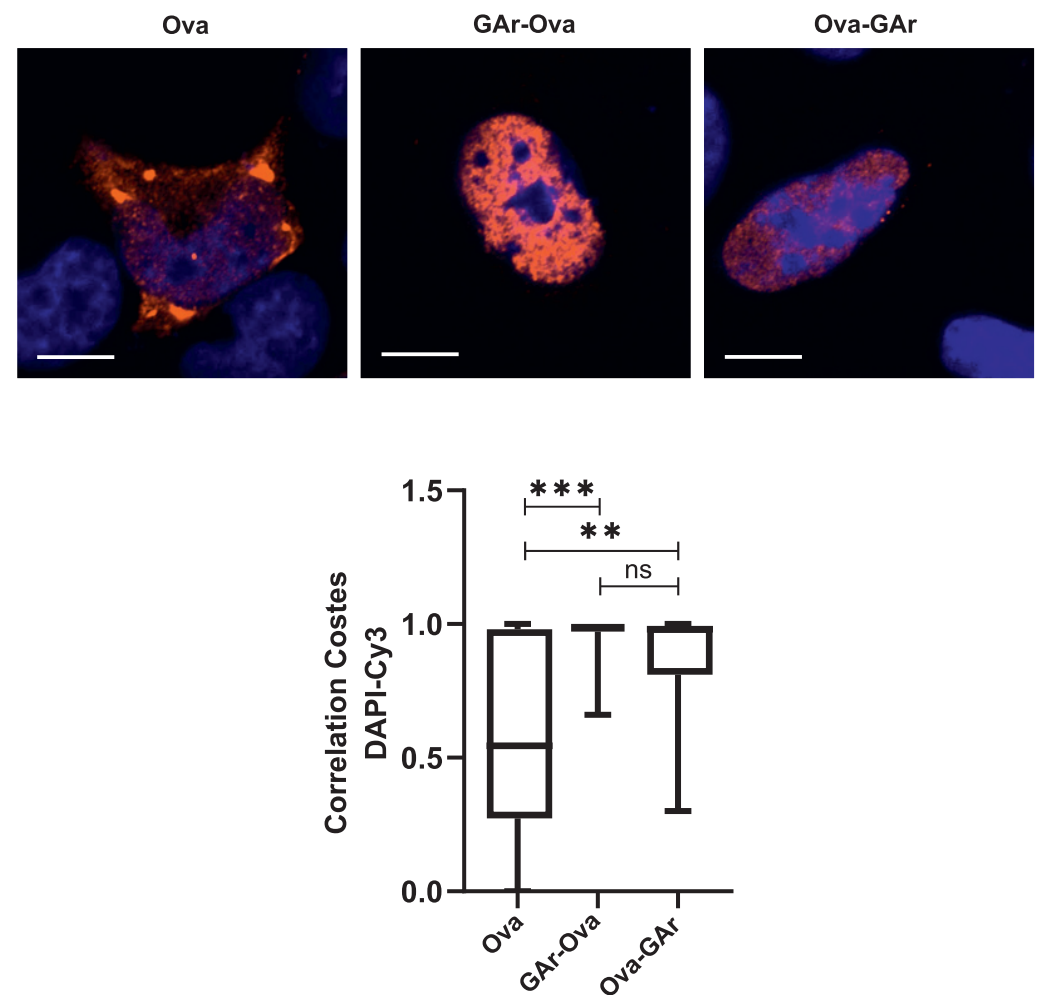

In vitro RNA-Nucleolin colP

Protein levels

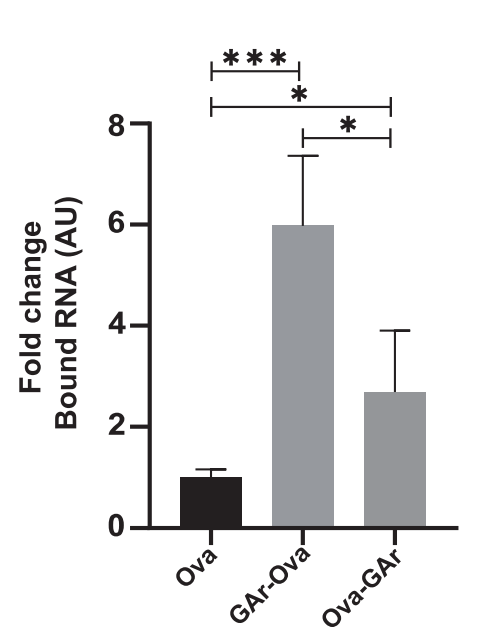

Figure 5. The position of $\mathrm{G} 4 \mathrm{~S}$ within the coding sequence affects their respective activities.

(A) Illustrations of the cDNA constructs to which GAr was fused to the N terminus (GAr-Ova) or C terminus (Ova-GAr) of chicken ovalbumin (Ova). Circles underneath represent the predicted RNA G4 structures for each construct (2 for Ova, 34 for GAr-Ova, and 33 for Ova-GAr). (B) Western blot of H1299 cells after transfection with indicated cDNA constructs. Graph shows relative expression adjusted with the corresponding actin levels. WB shows one of at least three similar experiments. (C) Ovaencoding mRNA localisation (RNA FiSH) in H1299 cells transfected with indicated constructs. Scale bar represents $10 \mu \mathrm{m}$. (D) Relative binding of Ova fusion mRNAs to recombinant NCL protein measured by in vitro RNA co-IP assay. mRNAs were extracted from H1299 cells transfected with indicated constructs. The graphs show the average of three independent experiments. 
A

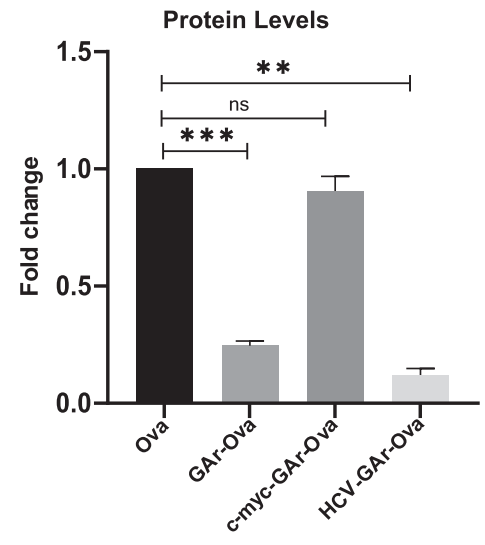

C

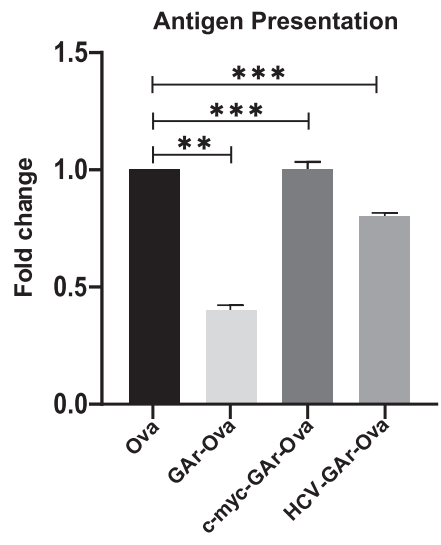

E

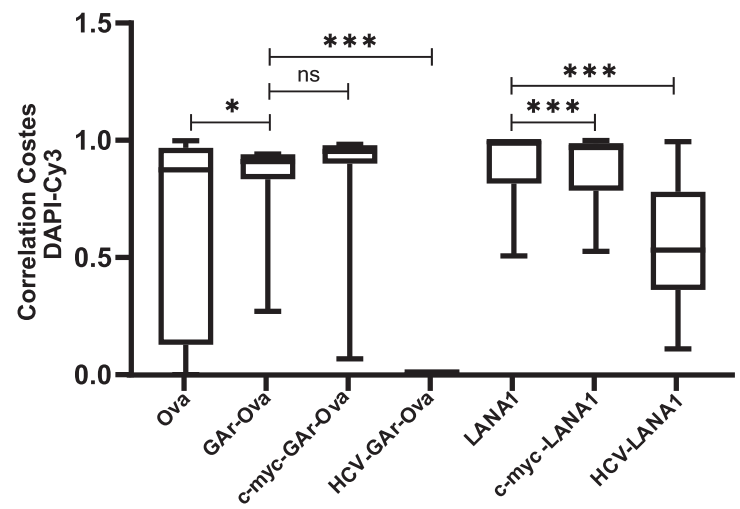

B

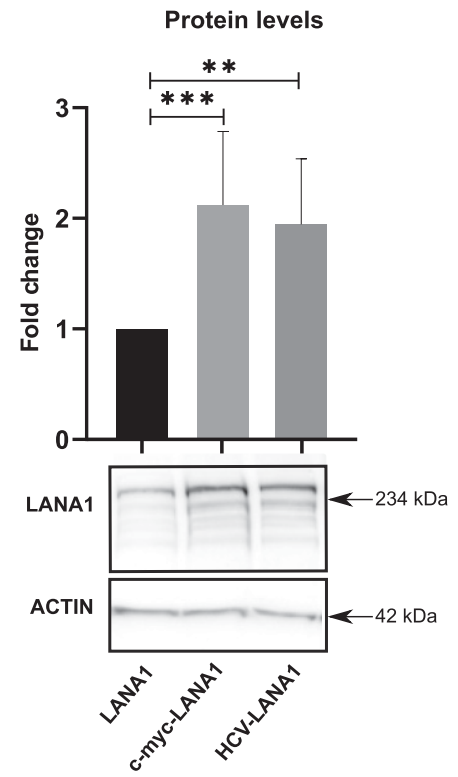

D

Antigen Presentation

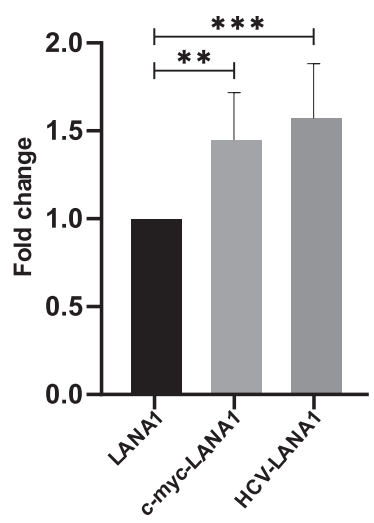

$\mathbf{F}$

PLA

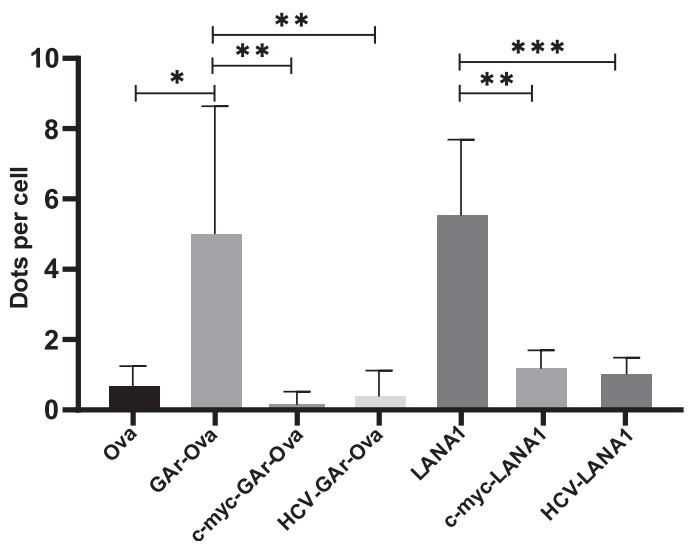

Figure 6. Altering the UTRs differentiates the activities of the GAr-encoded and LANA1 G4s.

Structured RNA sequences from the $5^{\prime}$ of the $c$-myc and the HCV were inserted in the $5^{\prime}$ of indicated constructs. (A) WB of H1299 cell lysates after transfection with indicated Ova fusion constructs. GAPDH was used as loading control. (B) WB of H1299 cell lysates after transfection with indicated LANA1 fusion constructs. (C) Antigen presentation levels estimated by measuring IL2 release by OT1 cells after incubation with H1299 cells transfected with GAr fusion constructs together with cDNA encoding murine MHC-I (Kb). (D) Antigen presentation levels derived from LANA1 fusion constructs. (E) Graph from RNA FiSH observations shows the median subcellular colocalisation of indicated mRNAs with the nucleus. (F) Graph shows proximity ligation assay data about the interaction between NCL and indicated mRNAs from transfected constructs in H1299 cells. The graphs show the values of three independent experiments. 
controlling the synthesis of antigenic peptides is in line with previous observations (Kwun et al, 2007). However, the results presented here do not support the $\mathrm{CR}$ domains being the sole responsible for controlling synthesis of antigenic peptides and fulllength proteins from the LANA1 mRNA. Nevertheless, we did not analyse the role of the individual LANA1 repeat domains and together with the fact that flanking sequences play a role in determining $\mathrm{G} 4$ activities this can help in explaining this discrepancy.

An important conclusion from this study is that different $\mathrm{G} 4$ activities within an mRNA can be differentiated by altering flanking sequences, illustrating the dynamic nature of G4 RNA structures. For example, moving the GAr sequence from the $5^{\prime}$ towards the 3' end of the coding sequence reduces its translation inhibitory capacity and NCL binding without affecting nuclear retention. Introducing the structured RNAs of the HCV or the c-myc IRESs affect LANA1 and GAr mRNA translation and localisation differently. The HCV IRES further suppressed synthesis of GAr-carrying mRNAs, whereas it instead stimulated LANA1 expression and released the nuclear retention of both mRNAs. The c-myc IRES, on the other hand, does not affect RNA localisation but induces translation of both messages (Martins et al, 2019). Also G4-mediated regulation of canonical translation producing full-length proteins and non-canonical translation linked to antigenic peptides synthesis could be separated by introducing the HCV IRES in the 5' of the GAr.

Previous works show that RNA G4 structures can fold, unfold and refold in cellulo (Biffi et al, 2014; Chen et al, 2018; Yang et al, 2018). The EBNA1 message does not contain introns but placing the GAr in the context of a gene prevents NCL access in cellulo. However, placing the GAr in this context does not affect the G4 structure and RNAs isolated from cells interact with recombinant NCL (Martins et al, 2019). The interaction between the GAr derived from a spliced construct and NCL was observed in the cytoplasm when the nuclear localisation signal of NCL was removed (Martins et al, 2019). As the spliced message is subjected to the pioneer round of translation, the GAr G4S would have had to refold to allow NCL interaction in the cytoplasm. These observations indicate that the function of $\mathrm{G} 4 \mathrm{~S}$ in the regulation of mRNA processing is strongly influenced by events taking place during the mRNA maturation process and that they can act both in the nucleus as well as in the cytoplasm. In this context, G4S multifunctionality might be affected by any change impacting the nature of the ribonucleoparticles. In fact, several RNA binding proteins are reported to be involved in the folding and unfolding of G4S RNA for a specific regulation event (Wolfe et al, 2014; Herviou et al, 2020; Vannutelli et al, 2020).

The role, and actual in vivo existence, of G4 RNA structures is controversial (Guo \& Bartel, 2016; Waldron et al, 2018; Dumas et al, 2021). Our data support a model in which G4 structures form dynamic multifunctional units, showing similarity to the concept of intrinsic disordered proteins. The allosteric conformation of intrinsic disordered proteins is regulated by post-translational modifications and/or ligand binding that alter their interactomes and their functions (Habchi et al, 2014; Borkosky et al, 2017). The RNA G4S could follow a similar scheme, in which ligand binding, or RNA modifications, could affect the structure of the G4S and alter their activity. In the examples described here, the activities of the LANA1 and EBNA1 G4S can be disrupted by chemical ligands, by moving their position or by changing flanking sequences.
It is conceivable that the dynamic multifunctional roles of these herpes viral RNA G4S are not unique but reflect a more common nature of regulated RNA structures within coding sequences. In the case of the p53 mRNA, a structured region in the $5^{\prime}$ of the coding sequence is folded during genotoxic stress so that it binds to MDM2 and stimulates p53 synthesis. The RNA folding is prevented by a single cancer-derived synonymous mutation, illustrating how single nucleotides can affect the folding of an mRNA and its interaction with regulatory proteins (Candeias et al, 2008; Naski et al, 2009). In line with this, modifications of mRNAs can result in structural changes and, consequently, affect their functions and interactions with cellular factors (Lewis et al, 2017). For example, the binding of hnRNPC to cryptic U-tract sequences can be made available via N6-methylation on adenosine residues (Liu et al, 2015).

Treatment with chemical G4 ligands PhenDC3 or PhenDH2 disrupts GAr and LANA1 G4S functions. However, the PDS G4 ligand stimulates the inhibition of EBNA1 synthesis in vitro (Murat et al, 2014) but not in vivo and it does not affect NCL binding (Lista et al, 2017b; Martins et al, 2018). Such differences are also observed for LANA1. Dabral et al (2019) report that the G4-stabilising ligand TMPYP 4 reduces the translation of LANA1 MRNA, but we show here that PhenDC3 or PhenDH2 treatments increase LANA1 protein expression and the presentation of LANA1-derived antigens. It is, thus, likely that different G4 ligands affect RNA structures differently by being able to either stabilise or destabilise them and/or to interfere with their ability to represent binding platforms for various RNAbinding factors. Considering the dynamic function of the herpes viral G4S, this suggests that G4 structures and activities can be specifically targeted for therapeutic intervention and that screening of G4-targeting compounds should be carried out in an in vivo setting with an intact message to obtain a specific activity.

\section{Materials and Methods}

\section{Annealing of RNA sequences for CD spectroscopy}

The G-rich RNA oligonucleotide (ON) sequences LANA13 (5'AGGAGGUGGAGGA), genomic loci 2563, G-score 21, and LANA16 (5'AGGAGCAGGAGGUGGA, genomic loci 2635, G-score 18) (Dabral et al, 2019) were purchased in Eurogentec as lyophilized solid after HPLC separation. They were reconstituted in DEPC water, and their concentration calculated by measuring the UV absorption at $260 \mathrm{~nm}$ on a Hitachi 2900 spectrometer. RNA ON buffered solutions (5 $\mu \mathrm{M}$ ON; Li Cacodylate $10 \mathrm{mM}, \mathrm{KCl} 100 \mathrm{mM}$ ) were annealed in a thermo-block by heating $2 \mathrm{~min}$ at $95^{\circ} \mathrm{C}$ and let it cool until reaching room temperature.

\section{CD footprint}

The CD of the previously annealed ON sequences (LANA13 and LANA16) were measured alone or in the presence of $2 \mathrm{M}$ equivalents of PhenDC3 or PhenDH2 in a Jasco J-1500 CD spectrometer using a quartz cuvette of $0.5-\mathrm{cm}$ path length. The parameters were four accumulations, CD scale 200 mdeg/0.1 dOD, scanning speed 100 $\mathrm{nm} / \mathrm{min}$. The spectra shown were mathematically processed using 
the Savitzky-Golay method with 20 points of window (del VillarGuerra et al, 2017).

\section{CD melting}

The CD melting of the ON sequences containing (LANA13 and LANA16), alone or in the presence of ligand, were monitored using a Jasco J-1500 CD spectrometer equipped with external temperature water-circuit control. The CD was recorded at 262 and $295 \mathrm{~nm}$ every $0.2^{\circ} \mathrm{C}$ change, when heating the samples from $20^{\circ} \mathrm{C}$ to $95^{\circ} \mathrm{C}$ at a speed of $0.2^{\circ} \mathrm{C} / \mathrm{min}$.

\section{UV melting}

The UV melting of the ON sequences containing (LANA13 and LANA16) in absence of ligand were monitored using a Spectro UV Cary-300 equipped with external temperature water-circuit control. The UV was recorded at $295 \mathrm{~nm}$ when heating the samples from $20^{\circ} \mathrm{C}$ to $95^{\circ} \mathrm{C}$ at a speed of $0.2^{\circ} \mathrm{C} / \mathrm{min}$.

\section{Expression plasmids}

Putative G4 RNA sequences were identified in the LANA1-encoding and Ova-encoding mRNAs using the QGRS Mapper: https:// bioinformatics.ramapo.edu/QGRS/index.php (Kikin et al, 2006).

All expression plasmids were constructed using the pcDNA3 vector and amplified in the Escherichia coli $\mathrm{DH} 5 \alpha$ strain. The constructs named Ova, GAr-Ova and Ova-GAr encode the following proteins, respectively: Ovalbumin without the first 50 amino acids, the same protein with the GAr domain from EBNA1 fused to its $\mathrm{N}$ terminus or C terminus (Yin, 2003).

The PA3F-LANA1 plasmid carrying the Flag-tagged ORF73 of KSHV in pcDNA3 vector, which encodes wild-type LANA1 protein, was a kind gift from Pr. Blondel (University of Brest). LANA1-SL8 construct was created by inserting the SL8 (SIINFEKL peptide from chicken ovalbumin) coding sequence after the C-terminal domain of LANA1. LANA1 $\triangle C R-S L 8$ construct was generated using the QuikChange SiteDirected Mutagenesis System (Stratagene) and the construct LANA1-SL8 as template.

The plasmids c-myc_IRES_Ova, c-myc_IRES_GAr-Ova, HCV_IRES_Ova, and HCV_IRES_GAr-Ova encode Ovalbumin or a fusion of the GAr domain to the $\mathrm{N}$ terminus of ovalbumin, with either the c-myc IRES or the HCV IRES in their 5' UTR (Apcher et al, 2009). HCV and c-myc IRES were amplified from these constructions and fused to the $5^{\prime}$ UTR or 3' UTR of LANA1-SL8 plasmid to produce the 5' c-myc-IRES-LANA1, 3' c-myc-IRES-LANA1, 5' HCV-IRES-LANA1, and 3' HCV-IRES-LANA1 constructs. The list of primers, cloning method, and resulting plasmids is provided in Table S1.

\section{Cell culture}

The human lung carcinoma cell line H1299 and the EBV-infected B cell line B95.8 were cultured in RPMI 1640 medium supplemented with $10 \%$ FBS, $2 \mathrm{mM} \mathrm{L}$-glutamine, $100 \mathrm{U} / \mathrm{ml}$ penicillin and $100 \mu \mathrm{g} / \mathrm{ml}$ streptomycin. KSHV-infected BCP-1 cell line was cultured in RPMI medium containing 10\% FBS, 4 mM L-glutamine, $100 \mathrm{U} / \mathrm{ml}$ penicillin,
$100 \mu \mathrm{g} / \mathrm{ml}$ streptomycin, and $5 \mathrm{mM}$ Hepes. All cells were cultured at $37^{\circ} \mathrm{C}$ in a humidified $5 \% \mathrm{CO}_{2}$ incubator.

\section{Transfection and drug treatment}

H1299 cells were seeded in six-well plates $\left(7 \times 10^{4}\right.$ cells/well) and transient transfections were carried out 20-24 h later using the Genejuice reagent (Merck Bioscience) according to the manufacturer's protocol. For cell treatments with PhenDC3, PhenDH2, and PDS (Lista et al, 2017b; Reznichenko et al, 2019), cells were incubated with $2 \mu \mathrm{M}$ of drug $24 \mathrm{~h}$ after transfection. Drug stock solutions were prepared in DMSO (Euromedex).

\section{Western Blotting}

$40 \mathrm{~h}$ after transfection, cells were resuspended in lysis buffer (20 mM Hepes KOH, pH 7.5, 50 mM $\beta$-glycero-phosphate, 1 mM EDTA, pH 8, 1 mM EGTA, pH 8, $0.5 \mathrm{mM} \mathrm{Na}_{3} \mathrm{VO}_{4}, 100 \mathrm{mM} \mathrm{KCl}, 10 \%$ Glycerol, and $1 \%$ Triton $\mathrm{X}$-100) supplemented with complete protease inhibitor cocktail (Roche) and protein concentration was measured using a Bradford assay. Samples were separated by electrophoresis in Bolt Bis-Tris Plus gels 4-12\% (Invitrogen/Thermo Fisher Scientific), and then transferred onto nitrocellulose membrane (BioTrace NT, Pall Life Science). Membranes were blocked for $1 \mathrm{~h}$ in $5 \%$ non-fat dry milk in Tris-buffered saline, pH 7.6, containing $0.1 \%$ Tween-20. Proteins were probed by overnight incubation at $4^{\circ} \mathrm{C}$ with the following antibodies: anti-Ovalbumin whole serum (C6534; SigmaAldrich), anti- $\beta$-actin mouse monoclonal antibody (clone AC-15; Sigma-Aldrich), anti-NCL polyclonal rabbit antibody (ref 22758; Abcam), anti-Flag mouse monoclonal antibody (F3165; SigmaAldrich), anti-EBNA1 mouse monoclonal antibody OT1X (Cyto-Barr BV), and anti-LANA1 (KSHV ORF73) mouse monoclonal antibody (D325-3; MBL International). Membranes were then incubated with appropriate HRP-conjugated secondary antibodies (Dako) and detection of immune complexes was performed using Pierce ECL, WestDura, or West Femto (Thermo Fisher Scientific) and myECL Imager (Thermo Fisher Scientific). Protein bands were quantified by densitometry analysis in Fiji/ImageJ (Schneider et al, 2012), using actin bands for normalisation.

Predicted molecular weight for the full-length LANA1 is $135 \mathrm{kD}$; however, as it was previously described, the LANA1 full-length protein migrate at $234 \mathrm{kD}$ in SDS-PAGE (Rainbow et al, 1997). In addition, the LANA1 $\triangle C R$ product is predicted to have a molecular weight of $61 \mathrm{kD}$, but migration with SDS-PAGE resulted in an observed band of $100 \mathrm{kD}$.

\section{RNA FiSH}

H1299 cells were seeded in 24-well plates $\left(2 \times 10^{4}\right.$ cells/well) and transient transfections were carried out 20-24 h later using the Genejuice reagent (Merck Bioscience) according to the manufacturer's protocol. $24 \mathrm{~h}$ after transfection or after drug treatment, the cells were briefly washed with ice-cold PBS, fixed with 4\% PFA during $20 \mathrm{~min}$ at room temperature, and washed again with PBS. Cells were then incubated in $70 \%$ ethanol for $4-24 \mathrm{~h}$ at $4^{\circ} \mathrm{C}$, after intermediate dehydrating steps using $30 \%$ and $50 \%$ ethanol. For rehydration, the cells were incubated in 50\% and 30\% ethanol and 
further washed with PBS. Subsequently, cells were permeabilised with PBS $0.4 \%$ Triton $0.05 \%$ CHAPS for 5 min at room temperature. After three PBS washes, samples were pre-treated with two subsequent incubations in FiSH wash buffer (10\% formamide and $2 \mathrm{X}$ SSC in $\mathrm{dd}_{2} \mathrm{O}$ ) for $10 \mathrm{~min}$ and then in FiSH hybridisation buffer $(10 \%$ formamide, 2X SSC, $2 \mathrm{mg} / \mathrm{ml}$ BSA, $0.2 \mathrm{mg} / \mathrm{ml}$ E. coli tRNA, $0.2 \mathrm{mg} / \mathrm{ml}$ sheared salmon sperm DNA) for $30 \mathrm{~min}$ at room temperature. Coverslips were then incubated overnight in a wet chamber at $37^{\circ} \mathrm{C}$ in FiSH hybridisation buffer supplemented with $10 \%$ dextran sulphate and $100 \mathrm{nM}$ of FiSH Stellaris probes targeting Ovalbumin or LANA1 mRNAs (Biosearch Technologies). Coverslips were washed twice 20 min in FiSH hybridisation buffer and 5 min in FiSH Wash buffer and subsequently stained with DAPI. Samples were mounted using Dako mounting solution (Dako) and observed with a LSM 800 (Zeiss) confocal laser microscope. Images were obtained using Zen software (Zeiss) and the Costes colocalisation factor between nuclei (DAPI channel) and targeted mRNAs (Cy3 channel), called Correlation_Costes_DAPI_Cy3, were obtained using the software CellProfiler (McQuin et al, 2018), and later used for statistical analysis.

\section{Proximity ligation assay (RNA-protein)}

Cells were cultured, fixed, permeabilised, and submitted to a prehybridisation step as described above. For target-mRNAs hybridisations, DNA probes were denatured for $5 \mathrm{~min}$ at $80^{\circ} \mathrm{C}$ and diluted in hybridisation buffer at a concentration of $50 \mathrm{ng}$ of probes per sample. The probes 5' GCAGCAGACTACACCTCCACACTCACC-biotin $3^{\prime}$ and 5'CTGCTTCATTGATTCTGCATGTGCTGCATGGACAGCTTGAAAAA-digoxigenin 3' were designed to target LANA1 and Ovalbumin mRNAs, respectively. Samples were overnight incubated with the denatured DNA probes in a wet chamber at $37^{\circ} \mathrm{C}$. Samples were then washed in hybridisation buffer, FiSH wash buffer, and PBS and saturated with PBS 3\% BSA 0.1\% saponin for $1 \mathrm{~h}$ at room temperature. Primary antibodies were diluted in the saturation solution, kept for $30 \mathrm{~min}$ at room temperature and then overnight incubated with tested samples at $4^{\circ} \mathrm{C}$ in a wet chamber. The following antibodies were used to perform the PLA: anti-Digoxigenin mouse monoclonal antibody (clone DI-22, D8156; Sigma-Aldrich), antiBiotin mouse monoclonal (clone BN-34, B7653; Sigma-Aldrich), and antiNCL rabbit polyclonal antibody (ab22758; Abcam). Afterwards, PLA was performed using Duolink PLA kit and plus/minus probes (Sigma-Aldrich) following the manufacturer's instructions. Coverslips were finally mounted using Dako mounting buffer (Dako) after nuclear staining with DAPI and observed using an LSM 800 confocal laser microscope. Images were obtained using the Zen software and analysed using Fiji/ImageJ.

\section{Antigen presentation}

Naive OVA257-264-specific CD8 ${ }^{+}$T-cells were isolated from the peripheral and mesenteric lymph nodes of OT-I-mice using the $\mathrm{CD}^{+}$-isolation kit (Miltenyi Biotec). Subsequently, $4 \times 10^{5} \mathrm{CD}^{+}$ T-cells were co-cultured with $10^{5} \mathrm{H} 1299$ cells previously transfected with the indicated constructs and a mouse $\mathrm{Kb}$ expression vector (a kind gift from C Watts, University of Dundee) and treated or not with the tested drugs. Cells were cultured in RMPI 1640 (Thermo Fisher Scientific) supplemented with $2 \mathrm{mM} \mathrm{L-glutamine,} 100 \mathrm{U} / \mathrm{ml}$ streptomycin and $100 \mathrm{U} / \mathrm{ml}$ penicillin (Invitrogen), 10\% FBS, $0.05 \mathrm{mM}$ 2-mercaptoethanol, and $5 \mathrm{mM}$ Hepes (Sigma-Aldrich) for $3 \mathrm{~d}$ at $37^{\circ} \mathrm{C}$ with $5 \% \mathrm{CO}_{2}$. Supernatants were collected from the co-cultures and IL-2 levels were measured by ELISA using ELISA MAX Standard kit (BioLegend) following the manufacturer's protocol. Signals were measured using a FLUOstar Optima (BMG Labtech) and data were analysed using the software Optima Control v2.20R2.

\section{RNA extraction, RT-qPCR, and RNA co-IP assay}

Transfected cells were washed in cold PBS and total RNA extraction was performed using RNAeasy mini Kit (QIAGEN), following the manufacturer's instructions. CDNA synthesis was carried out using the Moloney murine leukaemia virus M-MLV reverse transcriptase and Oligo(dT) 12-18 primer (Life technologies). qPCR was performed using the StepOne real-time PCR system (Applied Biosystems) with Perfecta SYBR Green FastMix (Quanta Biosciences) and the following primers (custom primers by Invitrogen): Actin Forward 5'-TCACCCACACTGTGCCCATCTACGA-3', Actin Reverse 5'-TGAGGTAGTCAGTCAGGTCCCG-3', LANA1 Forward: 5'-ATCTCCTGCATTGCCACCCACGC-3', LANA1 Reverse: 5'-TCTCAGGCTACGCAGGGTAGACG-3', Ova Forward 5'-GCAAACCTGTGCAGATGATG-3', Ova Reverse 5'CTGCTCAAGGCCTGAGACTT-3'. In vitro RNA co-IP was carried out as described elsewhere (Candeias et al, 2008). Briefly, $1 \mu \mathrm{g}$ of total RNA extracted from cells was co-incubated under agitation with $100 \mathrm{ng}$ of recombinant NCL (provided by Dr. Teulade-Fichou) in the binding buffer ( $50 \mathrm{mM}$ Tris, pH 7.5, $150 \mathrm{mM} \mathrm{NaCl}, 0.02 \mathrm{mg} / \mathrm{ml}$ yeast tRNA, and $0.2 \mathrm{mg} / \mathrm{ml} \mathrm{BSA}$ ) for $15 \mathrm{~min}$ at $37^{\circ} \mathrm{C}$. After incubation, NCL-RNA complexes were pulled down at $4^{\circ} \mathrm{C}$ using G-coated sepharose beads (Sigma-Aldrich) with an anti-NCL rabbit polyclonal antibodies (ab22758; Abcam) according to standard conditions and purified using the TRIzol (Life Technologies). Precipitated RNAs were then analysed by RT-qPCR.

\section{Statistical analysis}

Data were analysed by unpaired Mann-Whitney's test or $t$ test on GraphPad Prism 9. For Western blot, PLA dot counts, and qPCR analyses, represented data are the mean and the SD of a minimum of three independent experiments. For RNA co-IP analyses, represented data are the mean and the standard error of a minimum of three independent experiments. For FiSH analysis, data represented on graphs are the median value, $25 \%$ and $75 \%$ quartiles delimiting the interquartile range, the maximum and minimum values and the outliers. In all cases, $P>0.1234(\mathrm{~ns}), P<0.0332(*), P<$ $\left.0.0021^{(* *}\right)$, and $P<0.0002^{(* *)}$.

\section{Supplementary Information}

Supplementary Information is available at https://doi.org/10.26508/lsa. 202101232.

\section{Acknowledgements}

We thank the staff of the Plateforme Technologique de l'Institut de Recherche Saint-Louis for their help with microscopy. FUNDING: AJ-L Zheng 
was funded by Universite de Paris and the Fondation pour la Recherche Médicale (grant number FDT202001010912). This work was partially supported by European Regional Development Fund (ENOCH, CZ.02.1.01/0.0/0.0/ 16_019/0000868), MH CZ-DRO (MMCl, 00209805), Cancerforskningsfonden Norr, Cancerfonden (160598), Vetenskapsradet, and by the International Centre for Cancer Vaccine Science within the International Research Agendas program of the Foundation for Polish Science co-financed by the European Union under the European Regional Development Fund.

\section{Author Contributions}

AJ-L Zheng: investigation.

A Thermou: investigation.

P Guixens-Gallardo: investigation.

L Malbert-Colas: investigation.

C Daskalogianni: investigation.

N Vaudiau: investigation.

P Brohagen: investigation.

A Granzhan: investigation.

M Blondel: supervision.

M-P Teulade-Fichou: supervision.

RP Martins: supervision.

R Fahraeus: conceptualization.

\section{Conflict of Interest Statement}

The authors declare that they have no conflict of interest.

\section{References}

Apcher S, Daskalogianni C, Lejeune F, Manoury B, Imhoos G, Heslop L, Fahraeus R (2011) Major source of antigenic peptides for the MHC class I pathway is produced during the pioneer round of mRNA translation. Proc Natl Acad Sci U S A 108: 11572-11577. doi:10.1073/ pnas. 1104104108

Apcher S, Komarova A, Daskalogianni C, Yin Y, Malbert-Colas L, Fåhraeus R (2009) mRNA translation regulation by the Gly-Ala repeat of EpsteinBarr virus nuclear antigen 1. J Virol 83: 1289-1298. doi:10.1128/JVI.0136908

Arora A, Maiti S (2009) Differential biophysical behavior of human telomeric RNA and DNA quadruplex.J Phys Chem B 113: 10515-10520. doi:10.1021/ jp810638n

Aznauryan M, Noer SL, Pedersen CW, Mergny J, Teulade-Fichou M, Birkedal V (2021) Ligand binding to dynamically populated G-quadruplex DNA. ChemBioChem 22: 1811-1817. doi:10.1002/cbic.202000792

Ballestas ME (1999) Efficient persistence of extrachromosomal KSHV DNA mediated by latency-associated nuclear antigen. Science 284: 641-644. doi:10.1126/science.284.5414.641

Ballestas ME, Kaye KM (2001) Kaposi's sarcoma-associated herpesvirus latency-associated nuclear antigen 1 mediates episome persistence through cis-acting terminal repeat (TR) sequence and specifically binds TR DNA. / Virol 75: 3250-3258. doi:10.1128/JVI.75.7.32503258.2001

Beaudoin J-D, Novoa EM, Vejnar CE, Yartseva V, Takacs CM, Kellis M, Giraldez AJ (2018) Analyses of mRNA structure dynamics identify embryonic gene regulatory programs. Nat Struct Mol Biol 25: 677-686. doi:10.1038/ s41594-018-0091-z

Beaudoin J-D, Perreault J-P (2010) 5'-UTR G-quadruplex structures acting as translational repressors. Nucleic Acids Res 38: 7022-7036. doi:10.1093/ nar/gkq557
Beltran M, Tavares M, Justin N, Khandelwal G, Ambrose J, Foster BM, Worlock KB, Tvardovskiy A, Kunzelmann S, Herrero J, et al (2019) G-tract RNA removes Polycomb repressive complex 2 from genes. Nat Struct Mol Biol 26: 899-909. doi:10.1038/s41594-019-0293-z

Bezzi G, Piga EJ, Binolfi A, Armas P (2021) CNBP binds and unfolds in vitro G-quadruplexes formed in the SARS-CoV-2 positive and negative genome strands. Int J Mol Sci 22: 2614. doi:10.3390/ijms22052614

Biffi G, Di Antonio M, Tannahill D, Balasubramanian S (2014) Visualization and selective chemical targeting of RNA G-quadruplex structures in the cytoplasm of human cells. Nat Chem 6: 75-80. doi:10.1038/nchem.1805

Bohálová N, Cantara A, Bartas M, Kaura P, Štastný J, Pečinka P, Fojta M, Mergny J-L, Brázda V (2021) Analyses of viral genomes for G-quadruplex forming sequences reveal their correlation with the type of infection. Biochimie 186: 13-27. doi:10.1016/j.biochi.2021.03.017

Borkosky SS, Camporeale G, Chemes LB, Risso M, Noval MG, Sánchez IE, Alonso LG, de Prat Gay G (2017) Hidden structural codes in protein intrinsic disorder. Biochemistry 56: 5560-5569. doi:10.1021/ acs.biochem.7b00721

Candeias MM, Malbert-Colas L, Powell DJ, Daskalogianni C, Maslon MM, Naski N, Bourougaa K, Calvo F, Fåhraeus R (2008) P53 mRNA controls p53 activity by managing Mdm2 functions. Nat Cell Biol 10: 1098-1105. doi:10.1038/ncb1770

Cardinaud S, Moris A, Février M, Rohrlich P-S, Weiss L, Langlade-Demoyen P, Lemonnier FA, Schwartz O, Habel A (2004) Identification of cryptic MHC I-restricted epitopes encoded by HIV-1 alternative reading frames. J Exp Med 199: 1053-1063. doi:10.1084/jem.20031869

Ceci M, Fazi F, Romano N (2021) The role of RNA-binding and ribosomal proteins as specific RNA translation regulators in cellular differentiation and carcinogenesis. Biochim Biophys Acta Mol Basis Dis 1867: 166046. doi:10.1016/j.bbadis.2020.166046

Chen X-C, Chen S-B, Dai J, Yuan J-H, Ou T-M, Huang Z-S, Tan J-H (2018) Tracking the dynamic folding and unfolding of RNA G-quadruplexes in live cells. Angew Chem Int Ed 57: 4702-4706. doi:10.1002/anie.201801999

Ciufo DM, Cannon JS, Poole LJ, WU FY, Murray P, Ambinder RF, Hayward GS (2001) Spindle cell conversion by Kaposi's sarcoma-associated herpesvirus: Formation of colonies and plaques with mixed lytic and latent gene expression in infected primary dermal microvascular endothelial cell cultures. J VIROL 75: 5614-5626. doi:10.1128/ JVI.75.12.5614-5626.2001

Dabral P, Babu J, Zareie A, Verma SC (2019) LANA and hnRNP A1 regulate the translation of LANA mRNA through G-quadruplexes. I Virol 94: e01508-e01519. doi:10.1128/JVI.01508-19

del Villar-Guerra R, Gray RD, Chaires JB (2017) Characterization of quadruplex DNA structure by circular dichroism. Curr Protoc Nucleic Acid Chem 68: 17.8.1-17.8.16. doi:10.1002/cpnc.23

Dumas L, Herviou P, Dassi E, Cammas A, Millevoi S (2021) G-quadruplexes in RNA biology: Recent advances and future directions. Trends Biochem Sci 46: 270-283. doi:10.1016/j.tibs.2020.11.001

Duss O, Stepanyuk GA, Puglisi JD, Williamson JR (2019) Transient protein-RNA interactions guide nascent ribosomal RNA folding. Cell 179: 1357-1369.e16. doi:10.1016/j.cell.2019.10.035

Endoh T, Kawasaki Y, Sugimoto N (2013a) Stability of RNA quadruplex in open reading frame determines proteolysis of human estrogen receptor $\alpha$. Nucleic Acids Res 41: 6222-6231. doi:10.1093/nar/gkt286

Endoh T, Kawasaki Y, Sugimoto N (2013b) Suppression of gene expression by G-quadruplexes in open reading frames depends on G-quadruplex stability. Angew Chem Int Ed 52: 5522-5526. doi:10.1002/anie.201300058

Endoh T, Sugimoto N (2016) Mechanical insights into ribosomal progression overcoming RNA G-quadruplex from periodical translation suppression in cells. Sci Rep 6: 22719. doi:10.1038/srep22719 
Endoh T, Sugimoto N (2013) Unusual -1 ribosomal frameshift caused by stable RNA G-quadruplex in open reading frame. Anal Chem 85: 11435-11439. doi:10.1021/ac402497x

Fay MM, Lyons SM, Ivanov P (2017) RNA G-quadruplexes in biology: Principles and molecular mechanisms. J Mol Biol 429: 2127-2147. doi:10.1016/ j.jmb.2017.05.017

Fleming AM, Ding Y, Alenko A, Burrows CJ (2016) Zika virus genomic RNA possesses conserved G-quadruplexes characteristic of the Flaviviridae family. ACS Infect Dis 2: 674-681. doi:10.1021/ acsinfecdis.6b00109

Gnanasundram SV, Pyndiah S, Daskalogianni C, Armfield K, Nylander K, Wilson JB, Fåhraeus R (2017) PI3K $\delta$ activates E2F1 synthesis in response to mRNA translation stress. Nat Commun 8: 2103. doi:10.1038/s41467-017-02282-w

Guo JU, Bartel DP (2016) RNA G-quadruplexes are globally unfolded in eukaryotic cells and depleted in bacteria. Science 353: aaf5371. doi:10.1126/science.aaf5371

Habchi J, Tompa P, Longhi S, Uversky VN (2014) Introducing protein intrinsic disorder. Chem Rev 114: 6561-6588. doi:10.1021/cr400514h

Harris LM, Merrick CJ (2015) G-quadruplexes in pathogens: A common route to virulence control? PLoS Pathog 11: e1004562. doi:10.1371/ journal.ppat.1004562

Herdy B, Mayer C, Varshney D, Marsico G, Murat P, Taylor C, D'Santos C, Tannahill D, Balasubramanian S (2018) Analysis of NRAS RNA G-quadruplex binding proteins reveals DDX3X as a novel interactor of cellular G-quadruplex containing transcripts. Nucleic Acids Res 46: 11592-11604. doi:10.1093/nar/gky861

Herviou P, Le Bras M, Dumas L, Hieblot C, Gilhodes J, Cioci G, Hugnot J-P, Ameadan A, Guillonneau F, Dassi E, et al (2020) hnRNP H/F drive RNA G-quadruplex-mediated translation linked to genomic instability and therapy resistance in glioblastoma. Nat Commun 11: 2661. doi:10.1038/ s41467-020-16168-x

Jackson RJ, Hellen CUT, Pestova TV (2010) The mechanism of eukaryotic translation initiation and principles of its regulation. Nat Rev Mol Cell Biol 11: 113-127. doi:10.1038/nrm2838

Jaubert C, Bedrat A, Bartolucci L, Di Primo C, Ventura M, Mergny J-L, Amrane S, Andreola M-L (2018) RNA synthesis is modulated by G-quadruplex formation in Hepatitis C virus negative RNA strand. Sci Rep 8: 8120. doi:10.1038/s41598-018-26582-3

Ji D, Juhas M, Tsang CM, Kwok CK, Li Y, Zhang Y (2021) Discovery of G-quadruplex-forming sequences in SARS-CoV-2. Brief Bioinform 22: 1150-1160. doi:10.1093/bib/bbaa114

Kikin O, D'Antonio L, Bagga PS (2006) QGRS mapper: A web-based server for predicting G-quadruplexes in nucleotide sequences. Nucleic Acids Res 34: W676-W682. doi:10.1093/nar/gkl253

Kwun HJ, da Silva SR, Shah IM, Blake N, Moore PS, Chang Y (2007) Kaposi's sarcoma-associated herpesvirus latency-associated nuclear antigen 1 mimics epstein-barr virus EBNA1 immune evasion through central repeat domain effects on protein processing. J Virol 81: 8225-8235. doi:10.1128/JVI.00411-07

Lan K, Kuppers DA, Verma SC, Robertson ES (2004) Kaposi's sarcomaassociated herpesvirus-encoded latency-associated nuclear antigen inhibits lytic replication by targeting rta: A potential mechanism for virus-mediated control of latency. J Virol 78: 6585-6594. doi:10.1128/ JVI.78.12.6585-6594.2004

Lavigne M, Helynck O, Rigolet P, Boudria-Souilah R, Nowakowski M, Baron B, Guittat L, Beauvineau C, Petres S, Granzhan A, et al (2021) SARS-CoV-2 Nsp3 unique domain SUD interacts with guanine quadruplexes and G4-ligands inhibit this interaction. Nucleic Acids Res 49: 7695-7712. doi:10.1093/nar/gkab571

Lewis CJT, Pan T, Kalsotra A (2017) RNA modifications and structures cooperate to guide RNA-protein interactions. Nat Rev Mol Cell Biol 18: 202-210. doi:10.1038/nrm.2016.163
Lin JQ, van Tartwijk FW, Holt CE (2020) Axonal mRNA translation in neurological disorders. RNA Biol 18: 936-961. doi:10.1080/ 15476286.2020 .1822638

Lista MJ, Martins RP, Angrand G, Quillévéré A, Daskalogianni C, Voisset C, Teulade-Fichou M-P, Fåhraeus R, Blondel M (2017a) A yeast model for the mechanism of the Epstein-Barr virus immune evasion identifies a new therapeutic target to interfere with the virus stealthiness. Microb Cell 4: 305-307. doi:10.15698/mic2017.09.590

Lista MJ, Martins RP, Billant O, Contesse M-A, Findakly S, Pochard P, Daskalogianni C, Beauvineau C, Guetta C, Jamin C, et al (2017b) Nucleolin directly mediates Epstein-Barr virus immune evasion through binding to G-quadruplexes of EBNA1 mRNA. Nat Commun 8: 16043. doi:10.1038/ncomms16043

Liu N, Dai Q, Zheng G, He C, Parisien M, Pan T (2015) N6-methyladenosinedependent RNA structural switches regulate RNA-protein interactions. Nature 518: 560-564. doi:10.1038/nature14234

Lyonnais S, Gorelick RJ, Mergny J-L, Le Cam E, Mirambeau G (2003) G-quartets direct assembly of HIV-1 nucleocapsid protein along single-stranded DNA. Nucleic Acids Res 31: 5754-5763. doi:10.1093/nar/gkg716

Majee P, Kumar Mishra S, Pandya N, Shankar U, Pasadi S, Muniyappa K, Nayak D, Kumar A (2020) Identification and characterization of two conserved G-quadruplex forming motifs in the Nipah virus genome and their interaction with G-quadruplex specific ligands. Sci Rep 10: 1477. doi:10.1038/s41598-020-58406-8

Marquet R, Baudin F, Gabus C, Darlix J-L, Mougel M, Ehresmann C, Ehresmann B (1991) Dimerization of human immunodeficiency virus (type 1) RNA: Stimulation by cations and possible mechanism. Nucleic Acids Res 19: 2349-2357. doi:10.1093/nar/19.9.2349

Marquet R, Paillart J-C, Skripkin E, Ehresmann C, Ehresmann B (1994) Dimerization of human immunodeficiency virus type 1 RNA involves sequences located upstream of the splice donor site. Nucleic Acids Res 22: 145-151. doi:10.1093/nar/22.2.145

Martins RP, Findakly S, Daskalogianni C, Teulade-Fichou M-P, Blondel M, Fåhraeus R (2018) In cellulo protein-mRNA interaction assay to determine the action of $\mathrm{G}$-quadruplex-binding molecules. Molecules 23: 3124. doi:10.3390/molecules23123124

Martins RP, Malbert-Colas L, Lista MJ, Daskalogianni C, Apcher S, Pla M, Findakly S, Blondel M, Fåhraeus R (2019) Nuclear processing of nascent transcripts determines synthesis of full-length proteins and antigenic peptides. Nucleic Acids Res 47: 3086-3100. doi:10.1093/nar/ gky1296

McQuin C, Goodman A, Chernyshev V, Kamentsky L, Cimini BA, Karhohs KW, Doan M, Ding L, Rafelski SM, Thirstrup D, et al (2018) CellProfiler 3.0: Next-generation image processing for biology. PLoS Biol 16: e2005970. doi:10.1371/journal.pbio.2005970

Métifiot M, Amrane S, Litvak S, Andreola M-L (2014) G-quadruplexes in viruses: Function and potential therapeutic applications. Nucleic Acids Res 42: 12352-12366. doi:10.1093/nar/gku999

Münz C (ed) (2015) Epstein barr virus volume 2: One herpes virus: Many diseases. In Current Topics in Microbiology and Immunology. Cham: Springer International Publishing. doi:10.1007/978-3-319-22834-1

Murat P, Zhong J, Lekieffre L, Cowieson NP, Clancy JL, Preiss T, Balasubramanian S, Khanna R, Tellam J (2014) G-quadruplexes regulate Epstein-Barr virus-encoded nuclear antigen 1 mRNA translation. Nat Chem Biol 10: 358-364. doi:10.1038/nchembio.1479

Naski N, Gajjar M, Bourougaa K, Malbert-Colas L, Fåhraeus R, Candeias MM (2009) The p53 mRNA-Mdm2 interaction. Cell Cycle 8: 31-34. doi:10.4161/cc.8.1.7326

Piekna-Przybylska D, Sharma G, Bambara RA (2013) Mechanism of HIV-1 RNA dimerization in the central region of the genome and significance for viral evolution. J Biol Chem 288: 24140-24150. doi:10.1074/jbc. M113.477265 
Rainbow L, Platt GM, Simpson GR, Sarid R, Gao SJ, Stoiber H, Herrington CS, Moore PS, Schulz TF (1997) The 222- to 234-kilodalton latent nuclear protein (LNA) of Kaposi's sarcoma-associated herpesvirus (human herpesvirus 8) is encoded by orf73 and is a component of the latencyassociated nuclear antigen. J Virol 71: 5915-5921. doi:10.1128/ JVI.71.8.5915-5921.1997

Reznichenko O, Quillévéré A, Martins RP, Loaëc N, Kang H, Lista MJ, Beauvineau C, González-García J, Guillot R, Voisset C, et al (2019) Novel cationic bis(acylhydrazones) as modulators of Epstein-Barr virus immune evasion acting through disruption of interaction between nucleolin and G-quadruplexes of EBNA1 mRNA. Eur J Med Chem 178: 13-29. doi:10.1016/j.ejmech.2019.05.042

Rodgers ML, Woodson SA (2019) Transcription increases the cooperativity of ribonucleoprotein assembly. Cell 179: 1370-1381.e12. doi:10.1016/ j.cell.2019.11.007

Ruggiero E, Tassinari M, Perrone R, Nadai M, Richter SN (2019) Stable and conserved G-quadruplexes in the long terminal repeat promoter of retroviruses. ACS Infect Dis 5: 1150-1159. doi:10.1021/ acsinfecdis.9b00011

Sanchez de Groot N, Armaos A, Graña-Montes R, Alriquet M, Calloni G, Vabulas RM, Tartaglia GG (2019) RNA structure drives interaction with proteins. Nat Commun 10: 3246. doi:10.1038/s41467-019-10923-5

Schneider CA, Rasband WS, Eliceiri KW (2012) NIH image to Image): 25 years of image analysis. Nat Methods 9: 671-675. doi:10.1038/nmeth.2089

Serganov A, Nudler E (2013) A decade of riboswitches. Cell 152: 17-24. doi:10.1016/j.cell.2012.12.024

Starck SR, OW Y, Jiang V, Tokuyama M, Rivera M, Qi X, Roberts RW, Shastri N (2008) A distinct translation initiation mechanism generates cryptic peptides for immune surveillance. PLoS One 3: e3460. doi:10.1371/ journal.pone.0003460

Tosoni E, Frasson I, Scalabrin M, Perrone R, Butovskaya E, Nadai M, Palù G, Fabris D, Richter SN (2015) Nucleolin stabilizes G-quadruplex structures folded by the LTR promoter and silences HIV-1 viral transcription. Nucleic Acids Res 43: 8884-8897. doi:10.1093/nar/gkv897

Vannutelli A, Belhamiti S, Garant J-M, Ouangraoua A, Perreault J-P (2020) Where are G-quadruplexes located in the human transcriptome? NAR Genomics Bioinforma 2: Iqaa035. doi:10.1093/nargab/lqaa035

Waldron JA, Raza F, Le Quesne J (2018) elF4A alleviates the translational repression mediated by classical secondary structures more than by
G-quadruplexes. Nucleic Acids Res 46: 3075-3087. doi:10.1093/nar/ gky108

Wang S-R, Min Y-Q, Wang J-Q, Liu C-X, Fu B-S, Wu F, Wu L-Y, Qiao Z-X, Song Y-Y, $X u$ G-H, et al (2016a) A highly conserved G-rich consensus sequence in hepatitis $\mathrm{C}$ virus core gene represents a new anti-hepatitis $\mathrm{C}$ target Sci Adv 2: e1501535. doi:10.1126/sciadv.1501535

Wang S-R, Zhang Q-Y, Wang J-Q, Ge X-Y, Song Y-Y, Wang Y-F, Li X-D, Fu B-S, Xu G-H, Shu B, et al (2016b) Chemical targeting of a G-quadruplex RNA in the ebola virus L gene. Cell Chem. Biol 23: 1113-1122. doi:10.1016/ j.chembiol.2016.07.019

Wei J, Kishton RJ, Angel M, Conn CS, Dalla-Venezia N, Marcel V, Vincent A, Catez F, Ferré S, Ayadi L, et al (2019) Ribosomal proteins regulate MHC class I peptide generation for immunosurveillance. Mol Cell 73: 1162-1173.e5. doi:10.1016/j.molcel.2018.12.020

Wolfe AL, Singh K, Zhong Y, Drewe P, Rajasekhar VK, Sanghvi VR, Mavrakis KJ, Jiang M, Roderick JE, Van der Meulen J, et al (2014) RNA G-quadruplexes cause elF4A-dependent oncogene translation in cancer. Nature 513: 65-70. doi:10.1038/nature13485

Yang SY, Lejault P, Chevrier S, Boidot R, Robertson AG, Wong JMY, Monchaud D (2018) Transcriptome-wide identification of transient RNA G-quadruplexes in human cells. Nat Commun 9: 4730. doi:10.1038/ s41467-018-07224-8

Yewdell JW, Dersh D, Fåhraeus R (2019) Peptide channeling: The key to MHC class I immunosurveillance? Trends Cell Biol 29: 929-939. doi:10.1016/ j.tcb.2019.09.004

Yin Y (2003) Self-inhibition of synthesis and antigen presentation by epsteinbarr virus-encoded EBNA1. Science 301: 1371-1374. doi:10.1126/ science.1088902

Zhao C, Qin G, Niu J, Wang Z, Wang C, Ren J, Qu X (2021) Targeting RNA Gquadruplex in SARS-CoV-2: A promising therapeutic target for COVID19? Angew Chem Int Ed 60: 432-438. doi:10.1002/anie.202011419

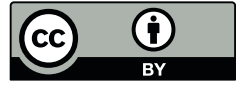

License: This article is available under a Creative Commons License (Attribution 4.0 International, as described at https://creativecommons.org/ licenses/by/4.0/). 